\title{
THE ECONOMICS OF COMMUTING AND THE URBAN LABOUR MARKET
}

\author{
Wayne Simpson \\ University of Manitoba \\ Anne van der Veen \\ University of Twente
}

\begin{abstract}
The spatial distribution of households and firms, or urban spatial structure, is a core element of the study of urban economics and the crucial determinant of commuting patterns. This paper examines developments in the analysis of urban spatial structure and commuting that are related to the urban labour market - that is the analysis of labour supply and labour demand in a spatial context. These developments have been overlooked in the traditional approach to urban structure and commuting where most attention has been devoted to the markets for land and housing rather than the market for labour. Yet a little reflection suggests that the labour market might have a great deal to do with the location decisions of households and firms, and hence with commuting patterns. We argue that much criticism of the economic analysis of urban structure and commuting can be addressed by explicit incorporation of the labour market into the conventional model of urban location. This criticism includes findings that the theory cannot explain the tendency for richer households to live farther from the central business district and commute farther to work (Wheaton, 1977) and findings of substantial unexplained or 'wasteful' commuting according to conventional theory (Hamilton, 1982). The paper begins by outlining the basic model of residential location and commuting (Section 2). We then consider extensions that involve the introduction of labour supply decisions and which determine the value of commuting time (Section 3 ). More recent extensions involve the introduction of decentralized workplaces (Section 4) and, logically, the issues of job search and migration (Section 5). We conclude with a summary of the progress in incorporating labour market behaviour into the analysis of urban structure and commuting and our suggestions for further research in this area.
\end{abstract}

Keywords: Commuting; urban structure; labour market; residential location; workplace location.

\section{Introduction}

The spatial distribution of households and firms, or urban spatial structure, is a core element of the study of urban economics. This spatial distribution in turn determines commuting patterns, which are important to urban transportation planning. This paper examines developments in the economic analysis of 
commuting which will be of interest to both urban economists and urban transportation planners.

The paper concentrates on developments in the analysis of urban spatial structure and commuting related to the urban labour market, that is the analysis of labour supply and labour demand in a spatial context. These developments have been overlooked in the traditional approach to urban structure and commuting. Considerable attention has been given to the markets for land and housing in urban areas but very little to the market for labour (e.g. Mills, 1987). Yet a little reflection suggests that the labour market might have a great deal to do with the location decisions of households and firms, and hence with commuting patterns. We believe that this is an oversight that merits a separate survey paper.

We argue that much criticism of the economic analysis of urban structure and commuting can be addressed by explicit incorporation of the labour market into the conventional model of urban location. This criticism includes Wheaton's (1977) findings that the theory cannot explain the tendency for richer households to live farther from the central business district and commute farther to work and Hamilton's (1982) finding of substantial unexplained or 'wasteful' commuting according to conventional theory.

The paper begins by outlining the basic model of residential location and commuting (Section 2). We then consider extensions that involve the introduction of labour supply decisions and which determine the value of commuting time (Section 3). More recent extensions involve the introduction of decentralized workplaces (Section 4) and, logically, the issue of workplace choice (Section 5). We conclude with a summary of the progress in incorporating labour market behaviour into the analysis of urban structure and commuting and our suggestions for further research in this area.

\section{The basic model}

The basic model of residential location and commuting is an extension of the standard problem of consumer choice involving two goods. Let $q$ be the amount of housing (or land, assuming expenditures on land and housing are proportional) and let $x$ be the amount of the Hicksian composite commodity, representing all other goods. The extension to the standard consumer choice model is the specification of costs for housing and commuting which differ according to location. Let all economic activity occur in the centre of the city (the monocentric city assumption) and let $h$ be the distance to the city centre. Then let the price gradient for housing be $p(h)$, which is exogenous to the individual consumer, and the cost of commuting be $c(h)$. These prices depend only on distance to the city centre, $h$ (the featureless plain assumption), where $\partial c / \partial h>0$. We now have a fairly simple consumer problem:

$$
\max U(q, x) \text { subject to } p(h) q+x+c(h)=y
$$

where $y$ is consumer income and the price of goods bundle $x$ is normalized. 
The standard first order conditions ${ }^{1}$ for a maximum are

$$
p(h)=\frac{\partial U / \partial q}{\partial U / \partial x}
$$

and

$$
\partial p / \partial h=-\frac{\partial c / \partial h}{q}<0
$$

Equation (3) is the equilibrium bid-rent schedule for the consumer, indicating that the household is willing to incur higher commuting costs per unit of land, $\partial c / \partial h / q$, provided that there is a compensating reduction in unit land costs, $\partial p / \partial h$. This trade-off between land and commuting costs is the fundamental insight of the basic model and early residential location literature.

The model introduces a third decision variable - commuting distance, $h$, which confers disutility on the consumer (or access to the city centre, $-h$, which confers utility). We can therefore write a solution to the consumer problem of $q, x$, and $h$ in terms of the parameters of the problem. In particular, we can write

$$
h=h[U(\cdot), p(\cdot), c(\cdot) ; y]
$$

to represent the consumer's locational equilibrium decision. If $U(\cdot), p(\cdot)$ and $c(\cdot)$ are the same for everyone, then differences in location will depend solely upon income, $y$. We can therefore obtain from the first order conditions (Siegel, 1975; Simpson, 1977)

$$
\frac{\partial h}{\partial y}=-\frac{\partial^{2} U / \partial x^{2}}{|A|}\left[(1-\eta) \frac{\partial p}{\partial h} \frac{\partial U}{\partial q}+\frac{\partial c}{\partial h} \frac{\partial^{2} U}{\partial q^{2}}\right]
$$

where

$$
A=\left(\begin{array}{cccc}
\frac{\partial^{2} U}{\partial q^{2}} & 0 & -\frac{\partial U}{\partial x} \frac{\partial p}{\partial h} & p \\
0 & \frac{\partial^{2} U}{\partial x^{2}} & 0 & 1 \\
-\frac{\partial U}{\partial x} \frac{\partial p}{\partial h} & 0 & -\frac{\partial U}{\partial x}\left(\frac{\partial^{2} p}{\partial h^{2}} q+\frac{\partial^{2} c}{\partial h^{2}}\right) & q \frac{\partial p}{\partial h}+\frac{\partial c}{\partial h} \\
p & 1 & q \frac{\partial p}{\partial h}+\frac{\partial c}{\partial h} & 0
\end{array}\right)
$$

and where $\eta=\left|\left(\partial^{2} U / \partial q^{2}\right) q / \partial U / \partial q\right|$ is the elasticity of the marginal utility of land (Alonso, 1964). From equation (5),

$$
\frac{\partial}{\partial \eta}\left(\frac{\partial h}{\partial y}\right)<0
$$


implying that consumers with more income will prefer to trade off more commuting for cheaper land if the elasticity $\eta$ is sufficiently small, a prediction which is in broad agreement with the pattern of settlement in American cities.

The role of income in residential location theory has always been considered to be crucial and has been the subject of several extensions to the analysis. A simple but interesting extension to the model assumes that the cost of commuting depends upon income (Muth, 1969, for example) so that

$$
c=c(h, y), \frac{\partial c}{\partial y}>0
$$

in consumer problem (1). Then the first order conditions do not change, but we can examine the effect of income on the bid-rent schedule (3):

$$
\frac{\partial}{\partial y}\left(\frac{\partial p}{\partial h}\right)=\frac{1}{q}\left[\frac{\partial}{\partial y}\left(-\frac{\partial c}{\partial h}\right)\right]-\frac{1}{q^{2}}\left[-\frac{\partial c}{\partial h} \frac{\partial q}{\partial y}\right]
$$

Let $M=-\partial c / \partial h$ be the marginal travel cost for any consumer. Then (7) can be rewritten

$$
\frac{\partial}{\partial y}\left(\frac{\partial p}{\partial h}\right)=\frac{M}{q y}\left[\eta_{M y}-\eta_{q y}\right]>0
$$

where $\eta_{M y}=\partial M / M / \partial y / y$ and $\eta_{a y}=\partial q / q / \partial y / y$ are the income elasticities of marginal travel cost and land respectively. Higher income implies a flatter bidrent schedule (since $\partial p / \partial h<0$ ) and, in a competitive bidding process, more distant locations from the centre (Alonso, 1964). Thus $\partial h / \partial y>0$ and, in particular,

$$
\frac{\partial}{\partial \eta_{q y}}\left(\frac{\partial h}{\partial y}\right)<0
$$

which agrees with equation (6).

How does income affect the cost of commuting? What Muth and others undoubtedly have in mind is a link between income and the value of commuting time as an important component of commuting cost. If we are to attach a value to commuting time, however, then commuting time should appear in the consumer's utility function. Moreover, commuting time cannot simply be included in the composite good $x$ in equation (1) for reasons that we articulate in the next section.

One potential solution to this problem is provided by assuming that commuting distance $h$ enters the utility function directly (Alonso, 1964; Wheaton, 1977):

$$
\max U(q, x, h) \text { subject to } p(h) q+x+c(h, y)=y
$$

The conditions implied by this problem are

$$
p(h)=\frac{\partial U / \partial q}{\partial U / \partial x}
$$


and

$$
\frac{\partial p}{\partial h}=\frac{1}{q}\left[\frac{\partial U / \partial h}{\partial U / \partial x}-\frac{\partial c}{\partial h}\right]
$$

In this case bid-rent schedules are steeper because of the monetized value of the disutility of commuting, given by $\partial U / \partial h / \partial U / \partial x$, which could reflect the value of commuting time when time is an unspecified function of distance. The effect of income on the bid-rent schedule is

$$
\frac{\partial}{\partial y}\left(\frac{\partial p}{\partial h}\right)=\frac{M}{q y}\left[\eta_{M y}-\eta_{q y}\right]>0
$$

where $M=\partial U / \partial h / \partial U / \partial x-\partial c / \partial h$ is now the total marginal cost of travel and $\eta_{M y}$ and $\eta_{y y}$ are defined as above. Thus the effect of income depends on the difference between the income elasticities of total marginal travel costs and land, $\eta_{M y}-\eta_{q y}$.

This analysis addresses the value of commuting time only indirectly. There is no explicit relationship between commuting distance and commuting time. More importantly, however, there is no specified relationship among commuting time, working time and leisure time. Any satisfactory discussion of the value of commuting time requires an analysis of the allocation of time among alternative users.

Empirical analysis called into question this basic theory of residential location as an explanation of location-income patterns in American cities. Muth (1969) found no relationship between distance from the city centre and household income in Chicago when age of the housing stock was included in his regression analysis. Later, Wheaton (1977) estimated the relationship between bid-rent schedules and income and found it to be too weak to explain the existing distinct location-income patterns of urban settlement in the United States.

Traditional analysis of residential location has provided many other extensions to the theory which involve analysis of the markets for land and housing (Straszheim, 1987, and Brueckner, 1987, for example). We take a different direction, concentrating on the consumer as a participant in the urban labour market. We argue that this is a fruitful line of enquiry that is generally overlooked in urban economic analysis. We have already indicated, for example, that we believe that it makes little sense to consider the value of commuting time, as analysts often do, without explicitly considering the allocation of time - a traditional topic in the economics of labour supply.

\section{The basic model and the allocation of time}

Hekman (1980) argues that the failure of the basic model to explain locationincome patterns rests on one crucial phenomenon, household labour supply. Labour supply cannot be ignored, or buried in the composite good $x$, because differences in income across households normally imply differences in earnings which in turn imply differences in the value of leisure. If the relative price of leisure to other goods changes, leisure cannot be included in the composite good 
and must be considered separately to permit substitution of leisure for other goods. Similarly, commuting time cannot be included in the composite good $x$ if its value varies with income across households.

Consider a single worker in the household ${ }^{2}$ and let his/her total time $T$ be divided into work time $L$, Leisure time $l$, and commuting time $t$. Commuting time and cost depend upon location and time spent working, which is assumed to be proportional to the number of worktrips, so that $t=t(L, h), \partial t / \partial L>0$, and $c=c(L, h), \partial c / \partial L>0$. The household receives earnings $w$ per time period and unearned income $y$ and maximizes a utility function which now includes leisure (Beckmann, 1974; Henderson, 1985):

$$
\begin{gathered}
\max U(q, x, l) \\
\text { subject to } p(h) q+x+c(L, h)=w L+y \\
\text { and } L(h)+l+t(L, h)=T
\end{gathered}
$$

The solution must satisfy the conditions that

$$
\begin{gathered}
p(h)=\frac{\partial U / \partial q}{\partial U / \partial x} \\
w=\frac{\partial U / \partial l}{\partial U / \partial x}
\end{gathered}
$$

and

$$
\frac{\partial p}{\partial h}=-\frac{\partial c / \partial h+w \partial t / \partial h+\partial c / \partial L \partial L / \partial h+w \partial t / \partial L \partial L / \partial h}{q}
$$

The equilibrium bid-rent schedule now depends upon direct commuting cost as in equation (3) but also upon commuting time, labour supply behaviour, and the wage rate.

Hekman concentrates on variation in the labour supply of households by income and location. Consider again the effect of household income on the bidrent schedule (17):

$$
\frac{\partial}{\partial y}\left(\frac{\partial p}{\partial h}\right)=\frac{M}{q y}\left[\eta_{M y}-\eta_{q y}\right]-\frac{1}{q y}\left[y \frac{\partial}{\partial y}\left(\frac{\partial c}{\partial L} \frac{\partial L}{\partial h}+w \frac{\partial t}{\partial L} \frac{\partial L}{\partial h}\right)-\eta_{q y}\right]
$$

where the total marginal cost of travel is now $M=-(\partial c / \partial h+w \partial t / \partial h)$. Wheaton (1977) finds that $\eta_{M y}-\eta_{q y} \approx 0$, but flatter bid-rent schedules may still arise as income increases if

$$
\frac{1}{q y}\left[y \frac{\partial}{\partial y}\left(\frac{\partial c}{\partial L} \frac{\partial L}{\partial h}+w \frac{\partial t}{\partial L} \frac{\partial L}{\partial h}\right)-\eta_{q y}\right]<0
$$

Clearly $\eta_{a y}>0$ as before so the question is whether

$$
\frac{\partial}{\partial y}\left(\frac{\partial c}{\partial L} \frac{\partial L}{\partial h}+w \frac{\partial t}{\partial L} \frac{\partial L}{\partial h}\right)<0
$$

Since $\partial c / \partial L>0$ and $\partial t / \partial L>0$, Hekman examines $\partial / \partial y(\partial L / \partial h)$. He finds that, 
as distance $h$ and income $y$ increase, labour supply falls dramatically for women and thus falls overall for the household. Thus expression (19) is negative - that is, greater distance and income are associated with reduced labour supply and lower total (direct and time) marginal costs of commuting. This result can account for flatter bid-rent curves, and residential locations farther from the centre, for higher income households. The crucial consideration ignored by Wheaton, and by the early versions of residential location theory, is labour supply behaviour.

The analysis introduces a second shift parameter, labour supply, into the analysis of commuting distance. Its direct effect can be easily seen by writing

$$
c(L, h)=K(L) C h
$$

and

$$
t(L, h)=K(L) D h
$$

where $K(L)$ is the number of commuting trips, which depends on labour supplied $(\partial K / \partial L>0), \mathrm{C}$ is the money cost per mile of a trip, and $D$ is the time spent per mile of a trip. From (21) we can rewrite the bid-rent schedule (17) as

$$
\frac{\partial p}{\partial h}=-\frac{K(L) C+w K(L) D+C h(\partial K / \partial L) \partial L / \partial h+w D h(\partial K / \partial L) \partial L / \partial h}{q}
$$

We can then examine the effect of labour supply on the bid-rent schedule. Assuming that the number of commuting trips is proportional to labour supply, so that $\partial^{2} K / \partial L^{2}=0$,

$$
\frac{\partial}{\partial L}\left(\frac{\partial p}{\partial h}\right)=-\frac{\partial K / \partial L+w D \partial K / \partial L}{q}<0
$$

Thus increased labour supply, meaning increased commuting, makes the (negatively sloped) bid-rent schedule of households steeper, other factors (income) held constant. Thus households with more labour supply, in particular households where there is a second earner (usually a married woman), will locate closer to the city centre to reduce commuting costs.

Hekman demonstrates the importance of labour supply decisions in accounting for residential location behaviour, but his analysis of commuting time is incomplete. Since commuting time does not enter the utility function, the value of commuting time must equal the value of leisure because the two uses of time are combined (Wales, 1978; Madden and White, 1980). ${ }^{3}$ While this represents some improvement over the models in the previous section, its validity can only be tested by explicit inclusion of commuting time in the utility function to assess its relative value.

As Kohlhase (1986) states, the attempt to endogenize all three uses of time greatly complicates the consumer problem. Thus she also argues for a model such as equation (14) which fixes commuting hours so that commuting time $t$ can be handled exogenously. Yet this cannot be satisfactory for any analysis of commuting decisions and residential location. 
The introduction of commuting time $t$ into the utility function immediately raises the problem of attaching a price to it. In the majority of the literature this is an unsolved problem. To our knowledge there are two exceptions. One way to find a price for commuting time, formulated by Oi (1976), is to relate the marginal utility of leisure proportionally to the marginal utility of commuting time. The sign of the parameter which links both marginal utilities then depends on whether commuting is seen as a disutility or as a utility. As far as we know, however, this construction has never been applied in empirical research.

Another solution to the problem of the value of commuting time has been formulated by Wales (1978). He includes commuting time directly in the utility function of the household:

$$
\begin{gathered}
\max U(q, x, l, t) \\
\text { subject to } p(t) q+x=w L+y \\
\text { and } L+l+t=T
\end{gathered}
$$

This specification combines equations (10) and (14) if we equate commuting time, $t$, and distance from the centre, $h$, in our monocentric city. ${ }^{4}$ The solution to the problem given by (24) must satisfy the conditions:

$$
\begin{gathered}
p(t)=\frac{\partial U / \partial q}{\partial U / \partial x} \\
w=\frac{\partial U / \partial l}{\partial U / \partial x}
\end{gathered}
$$

and

$$
w+q \frac{\partial p}{\partial t}=\frac{\partial U / \partial t}{\partial U / \partial x} \equiv v t
$$

where $v t$ is Wales' value of commuting time. Note that the value of commuting time includes both the wage rate, which is the marginal value of leisure from equation (16), and the reduction in housing expenditures arising from the additional time spent commuting. Since $q \partial p / \partial t<0$ in general (equation (3)), we expect that $v_{t}<w$, contrary to the implicit assumption that $v_{t}=w$ in other models where commuting time is excluded from the utility function.

By specifying a particular functional form for $p(t)$, namely

$$
p(t)=\beta t^{\gamma}
$$

then Wales obtains

$$
v_{t}=w+\frac{q \gamma p(t)}{t}
$$

where only $\gamma$ is unobserved in equation (29) for suitable household microdata. ${ }^{5}$ Inserting equation (29) into a Generalized Cobb-Douglas demand system for $q, x, l$, and $t$ and using Full Information Maximum Likelihood estimation yields an estimate of $\gamma$ of -0.1 and an estimate of $v_{t}$ for all households of $\$ 3.22$ per 
hour compared to an average wage rate of $\$ 4.72$ per hour. Wales concludes that 'on the average commuting time is valued at about two-thirds of the wage rate' (p. 222).

Wales' model is very elegant. It introduces commuting time $t$ into the utility function and it presents an estimate for the value of $t$. One problem, however, is that commuting time is specified as a utility with a positive price. It seems more realistic to specify commuting time as a disutility with a negative price. Moreover, commuting time in this model is seen as a product of residential relocation, but it is clear that workplace choice also affects commuting time. This topic will be discussed in the next two sections.

\section{The basic model with decentralized employment}

Employment in cities is decentralizing and the proportion of employment in central cities is declining dramatically (Kain, 1968; Mills, 1972; Scott, 1982). In the absence of a model that explicitly permits employment decentralization, empirical studies to test residential location models or to estimate the value of commuting time typically adapt the monocentric theory of the previous sections. A more suitable approach would be to formulate a model of residential location decisions with decentralized employment that would be suitable for testing and other empirical analysis.

The simplest adaptation of residential location models to incorporate decentralized employment is to assume some pre-determined work location for a given household. Then the residential location models of the previous sections can be used with one important addition. Commuting cost can simply be redefined in terms of distance (or time) to the work site rather than the city centre. If $j$ is the distance of the job from the city centre and $h$ is the distance of the home from the city centre, then we may write commuting cost as $c(h, j)$, where $\partial c / \partial h>0$ and $\partial c / \partial j<0$. The land price gradient must still refer to distance from the city centre, however, since the centre remains the most preferred site. We can then revise problem (1), or any of the subsequent extensions, to incorporate a non-central work site as follows:

$$
\max U(q, x) \text { subject to } p(h) q+x+c(h, j)=y
$$

The solution to this problem satisfies the same conditions (2) and (3) as our initial problem, but job location $j$ is now a parameter in the solution. In particular, we should write locational equilibrium condition (3) as

$$
\frac{\partial p}{\partial h}=-\frac{\partial c(h, j) / \partial h}{q}
$$

In principle, this does not change the equilibrium conditions if, for example, $\partial^{2} c / \partial h \partial j=0$. In the strict model we have defined, utility-maximizing households would reside farther from the city centre than their place of work on a ray from the city centre to obtain the lowest possible combination of commuting and land costs. Thus commuting distance would be $h-j$ and, if commuting costs were 
proportional to distance, $\partial^{2} c / \partial h \partial j=0$ so that condition $(31)$ is equivalent to condition (3).

The problem that arises is that all households prefer jobs located as far from the city centre as possible since these sites reduce total, if not marginal, commuting costs $(\partial c / \partial j<0)$. In the budget constraint in equation $(30)$, more distant work sites are equivalent to a higher income if households can choose work locations. Once the concept of decentralized employment is entertained, workplace choice becomes an important consideration.

The standard treatment of workplace choice is to introduce the concept of an urban wage gradient (Moses, 1962; Muth, 1969). More distant work sites are not preferred because wage offers at more distant sites are bid down until excess demand for those sites is eliminated. Thus an earnings or income gradient, $y(j)$, $\partial y / \partial j<0$, is introduced which leaves identical workers as well off at central a: at suburban work sites.

A simple extension is to permit job location to be a decision variable and to derive a wage gradient as well as a land price gradient. Recent models of this type have adopted models similar to specification (14), incorporating leisure in the utility function but ignoring the effect of labour supply on commuting cost and earnings (Straszheim, 1984; White, 1988) ${ }^{6}$ :

$$
\begin{gathered}
\max U[q(h, j), x(h, j), l(h, j)] \\
\text { subject to } p(h) q(h, j)+x(h, j)+w(j) l(h, j) \\
=w(j) T+y-[c(h, j)+w(j) t(h, j)]
\end{gathered}
$$

This model generates the usual conditions equivalent to equations (15) and (16). Using those conditions, the location equilibrium conditions for the places of residence and work can be written as

$$
\frac{\partial p}{\partial h}=-\frac{\partial c / \partial h+w \partial t / \partial h}{q}
$$

and

$$
\frac{\partial w}{\partial j}=\frac{\partial c / \partial j+w \partial t / \partial j}{T-t-l}=\frac{\partial c / \partial j+w \partial \tau / \partial j}{L}
$$

where $L(h, j)=T-t-l$ is hours worked as in equation (14).

Condition (33) appears to be equivalent to equation (17) when labour supply is omitted such that $\partial L / \partial h=0$. The one important difference is that the wage rate varies by job location as indicated by equation (34). Since $\partial c / \partial j<0$ and $\partial t / \partial j<0,{ }^{7} \partial w / \partial j<0$ in equation (34). Wage gradients have a negative slope like land price gradients. This means that otherwise identical households may have different rent offer curves because of differing job locations and that households with different job locations may segregate into different concentric residential rings (White, 1988, 143).

From equations (33) and (34) we may find an expression for the relative rate of decline of the wage and land price gradients:

$$
\frac{\partial w / \partial j}{w}=\frac{p q}{w L}\left(-\frac{\partial c / \partial j+w \partial t / \partial j}{\partial c / \partial h+w \partial t / \partial h}\right) \frac{\partial p / \partial h}{p}
$$


White specifies $c(h, j)=2 \mathrm{~m}(h-j)$, where $\mathrm{m}$ is direct commuting cost per unit of distance, and $t(h, j)=2 s(h-j)$, where $s$ is commuting time cost per unit of distance. One-way commuting distance is always $h-j$. Thus,

$$
-(\partial c / \partial j+w \partial t / \partial j)=2 m+2 s w=\partial c / \partial h+w \partial t / \partial h
$$

for White and the relative gradient decline is determined by the ratio of housing costs to earnings, $p q \mid w L$, or about 25 per cent. She concludes that wage offer curves will decline at about one-quarter of the rate that rent offer curves decline.

The problem with the model represented by equation (32), as with Hekman's (1980) model earlier, is that commuting time is excluded from the utility function. Thus commuting time must be subsumed as leisure and assigned a value equivalent to the value of leisure, despite evidence to the contrary (Wales, 1978 , for example). Thus, the ultimate model for location choice in a consumer demand framework should modify equation (32) to include commuting time $t(h, j)$ in the utility function to permit the value of commuting time to be determined as in equation (27).

Models with decentralized employment provide new and interesting predictions, particularly when the assumption of homogeneous households is relaxed. White $(1988,151)$ argues that households with more income will continue to commute farther but that residential location will be segregated on the basis of workplace location. Thus the ring of households in a particular income group commuting to a particular ring of workplace locations may be quite 'thin.' Households may only be indifferent to residential location within this narrow ring. If we introduce other dimensions of household heterogeneity, then these rings may be correspondingly thinner. In particular, White discusses the effect of differences in skill level. More skilled workers will have a higher wage and hence a higher value of commuting time from expression (32). ${ }^{8}$ This raises the skilled worker's wage offer curve - they demand higher wage compensation for longer in-commuting. Thus firms have a stronger incentive to locate in the suburbs the larger is the skilled work force as a proportion of total costs. Wage offer curves, and therefore wage gradients, will be steeper for skilled workers, a testable proposition that we will reconsider in the next section. Other interesting dimensions of household heterogeneity would include the number of workers, based on the importance of second-earner labour supply in location decisions as discussed in section 3 (equation (23)).

\section{Workplace choice and commuting}

The models in the previous section illustrate that, once decentralized employment is admitted, workplace choice must be introduced. In this section we evaluate the research on this issue to date and consider new avenues for research which focus on the urban labour market. In particular, we argue that the analysis to date is deficient in important respects and can be improved by turning to the vast literature on job search and workplace choice in labour economics. ${ }^{9}$ Since residential location theory is generally static, we focus on a 
static approach to workplace location, although there are natural extensions to a dynamic model of residential and workplace location decisions.

Some static models of workplace location have relied on a simplified version of model (32) in which residential location, $h$, is fixed and only job location, $j$, is to be determined. Locational equilibrium is then given by condition (34) in which the reservation wage of workers rises with commuting costs. That is, $\partial c / \partial j<0$ and $\partial t / \partial j<0$ implies $\partial w / \partial j<0$ in equation (34). Leonard (1987) expresses commuting costs for blacks in terms of distance from a monocentric black residential population, the ghetto. Then the farther that a firm is located from the ghetto, the less likely it is to employ blacks because black wage offers rise with distance from the ghetto. McCormick (1986) adds search costs but assumes only two employment locations. He derives the wage offer gradient as the ratio of wages at the two locations. In his model blacks commute longer distances because their moving costs are higher and because whites are more likely to receive preferred nearby jobs. Other research has implicitly adopted this approach of fixing residential location when analyzing the commuting behaviour of married women (Kain, 1962; Rees and Shultz, 1970; Beesley and Dalvi, 1974; Evers and van der Veen, 1986). ${ }^{10}$

This approach is unsatisfactory because residential location decisions are ignored. In addition, we argue that models based solely on the framework of residential location theory outlined in previous sections cannot provide an adequate basis to deal with both workplace and residential location. Consider the location equilibrium for residence and workplace generated from equations (33) and (34) in the previous section:

$$
\begin{aligned}
& h^{*}=h\left[q(\cdot), l(\cdot), p(\cdot), w(\cdot), c(\cdot), t(\cdot) ; y, j^{*}\right] \\
& j^{*}=j\left[q(\cdot), l(\cdot), p(\cdot), w(\cdot), c(\cdot), t(\cdot) ; y, h^{*}\right]
\end{aligned}
$$

These equations, derived from the consumer problem (32), are not identified in econometric terms because the equations contain the same set of independent variables. Models that focus only on the household do not generate distinct models of residential and workplace choice behaviour. In this sense the theory of workplace location is incomplete. To complete it requires the introduction of a model of the labour market in urban space. Consumer problem (32) provides an analysis of the wage offers of households (equation (34)) at any workplace location but ignores the wage offers made by firms. Yet the wage offers of firms may vary considerably across a city depending upon the size of the employment centre and local employment demand. It is these wage offers by firms coupled with the wage offers of households, more appropriately termed the reservation wages of households, ${ }^{11}$ that determine job choice and workplace location.

The wage offers of firms depend upon their labour requirements and those of their competitors. If there are many firms, or a few large firms seeking many workers, then wage offers will rise until vacancies are filled adequately. In particular, higher wage offers will expand the catchment area by compensating for commuting by more distant workers. Thus the central business district will 
normally have a larger catchment area, generated by higher wage offers, than smaller suburban employment centres. A wage gradient arises because employment density is greater relative to population density nearer the city centre, generating greater demand for labour and higher wage offers near to the city centre to attract more distant workers.

The simplest case in which to consider these concepts involves only two employment centres, a business district in the city centre and a suburban employment centre. Consider any individual located a distance $h$ from the city centre and a distance $l$ from the suburban (or local) employment centre. The simplest case, dictated by residential location equilibrium, is to assume that the suburban employment centre is on a line between the residential location and the city centre. Thus, $l<h$. Now divide the city into two districts or 'islands' consisting of $L_{c}$ workers living in the district that includes the city centre and $L_{l}$ workers living in the district that includes the suburban employment centre. Let there be $N_{c}$ jobs in the city centre and $N_{l}$ jobs at the suburban centre, where $N_{c}>N_{l}$. Labour market equilibrium requires

$$
N_{c}+N_{l}=L_{c}+L_{l}
$$

We can now introduce the labour supply behaviour of workers implied by equation (34). Workers prefer less commuting and must be compensated to undertake more commuting. Let $f(w, r)$ be the probability that a worker will accept a job involving commuting distance $r$ and offering wage $w$. Equation (34) implies that $\partial f / \partial w>0$ and $\partial f / \partial r<0$. Equilibrium in the suburban employment centre requires that the worker be offered a wage $w_{l}$ such that

$$
f\left(w_{l}, l\right)=N_{l} / L_{l} \equiv s
$$

where $s$ is jobs per resident worker in the suburban district. Since most of the jobs are in the centre, $s<1$ and all suburban employment requirements are filled by suburban residents. Some suburban residents must be lured to the city centre, however, by firms which pay a wage $w_{c}$ to attract them. Therefore, equilibrium also requires

$$
f\left(w_{c}, h\right)=\frac{N_{c}-L_{c}}{L_{l}}=1-s
$$

so that the remainder of the suburban workers are attracted to the central city. Then the expected commuting distance of the worker at distance $h$ from the centre and $l$ from the suburban employment centre is

$$
r=h-j=f\left(w_{l}, l\right) \cdot l+f\left(w_{c}, h\right) \cdot h=s \cdot l+(1-s) \cdot h
$$

such that $\partial r / \partial s=l-h<0$. If there are more jobs per resident worker in the suburban district, fewer suburban residents must leave their district to work and commuting declines.

Given $h$ and $l$, commuting distance varies with $s$, the ratio of local jobs to local residents who work. Thus, by rearranging equation (41), job location will depend 
upon local employment opportunities

$$
j=h-[h-s \cdot(h-l)]=s \cdot(h-l)
$$

such that $\partial j / \partial s=h-l>0$ and $\partial j / \partial h=s<1$. This provides us with a basic model of workplace choice that incorporates equation (34) and replaces equation (37) derived solely from residential and labour supply behaviour.

Because equations (39) and (40) capture the wage offer gradient in equation (34), they can be used to derive a wage gradient for the two islands in this model. In particular, $h>l$ mens that $w_{c}>w_{l}$ to compensate for more commuting to the city centre. The difference from earlier models is that the wage gradient now depends explicitly on the spatial distribution of jobs and workers between the two districts, captured by the variable $s$. Thus a city with a smaller suburban employment centre in relative terms (smaller $s$ ) will have a steeper wage gradient because central city firms will have to pay a larger premium to attract a larger proportion of suburban residents to central city jobs (as $s$ decreases, $w_{1}$ falls in equation (39) and $w_{c}$ rises in equation (40)). This is a feature of wage gradients that is likely to stand up to empirical scrutiny but that cannot be captured by models, such as those in section 4, which ignore urban labour demand and labour market equilibrium.

This simple model is extended by Simpson (1980). His model considers the city as a series of 'islands' or employment centres available to any worker. ${ }^{12} \mathrm{He}$ shows that the catchment area for firms ${ }^{13}$ grows as local employment demand relative to local workers $(s)$ increases and as local wage offers $(w)$ decline. Using a model of firms as dynamic monsponists, Simpson shows that wage rates rise as $s$ rises because of the competition for local workers. Since higher wage rates increase the probability of local workers accepting local jobs, expected commuting distance declines and expected work location $j$ rises as $s$ increases, just as in our simple model above.

Simpson (1980) also extends this model by considering the effect of skill level on job search behaviour. He argues that skill acquisition broadens the spatial extent of job search because it is partly non-enterprise-specific and restricts job choice. Skill acquisition therefore leads to more extensive formal search methods by both workers and employers. Thus, although the value of commuting time rises with wages and skill level (section 3), Simpson argues that skilled workers will be less responsive to local employment conditions than unskilled workers, contrary to predictions based only on the value of commuting time from models in previous sections. Evidence for Greater London (Simpson, 1980) and Toronto (Simpson, 1987 and 1989) from a simultaneous model of residential and workplace location estimated on cross-sectional household microdata supports this argument. In fact, Simpson's evidence for Toronto finds that his workplace choice equation is more important to the explanation of commuting behaviour than a standard residential location equation, ${ }^{14}$ particularly for recent job movers, second earners, and homeowners as would be expected.

Additional tests of this approach are possible. One straightforward test would be to estimate wage gradients for workers by skill level. The basic model with 
decentralized employment in section 4 predicts, based on the value of commuting time, that more skilled workers will have steeper wage gradients (e.g., White, $1988,149)$. Simpson's (1980) model, concentrating on job search in the urban labour market, predicts exactly the opposite - that more skilled workers will have flatter wage gradients. These nested hypotheses await direct testing with spatially disaggregated labour market activity microdata.

Evidence that workplace choice behaviour is an important aspect of commuting decisions can answer Hamilton's (1982) criticism that traditional residential location models leave a great deal of unexplained, or 'wasteful,' commuting in American and Japanese cities. Hamilton finds that commuters in the United States travel about eight times as far as necessary and commuters in Japan travel about three as far as necessary, based on minimum average commuting requirements estimated from population and employment density gradients. He argues that much of this wasteful commuting may arise because 'people may have found it in their interest to change jobs ... and found new jobs which do not conform to the optimization rules' (p. 1046). In other words, what is required is a theory of workplace location to supplement the conventional theory of residential location. He estimates that a workplace location theory may be able to explain commuting distances much better than residential location theory, a result which agrees with Simpson's (1987) analysis for Toronto.

\section{Concluding remarks}

Our paper has considered extensions to residential location theory and the analysis of urban commuting behaviour from what appears to be a unique perspective in urban economics - the perspective of the urban labour market. The paper argues that this perspective offers some important insights into the analysis of commuting behaviour and allows us to explain many empirical puzzles in the literature on the economics of commuting. In particular, we have argued that analysis of commuting behaviour should not ignore the allocation of time between work, commuting and leisure and it should not ignore workplace choice arising from the spatial variation in the demand for labour across urban areas. We believe that labour economics provides fertile ground to extend our understanding of the economics of commuting and urban spatial structure. Since meaningful integration of labour economics and urban spatial theory has not been vigorously pursued, much research remains to be done. Under the usual economic assumptions of diminishing returns, we expect that the benefits to research in this area remain very high at this early stage.

\section{Notes}

1. The second order conditions for a maximum are ensured by appropriate restrictions on the utility function.

2. The assumption of a single worker simplifies Hekman's analysis, which concentrates 
on the labour supply behaviour of women and, in particular, the labour supply of married women as second earners in households. His analysis effectively ignores male labour supply behaviour. Other studies which consider male and female labour supply separately include Oi (1976) and Kohlhase (1986).

3. We have already seen that leisure time and commuting time cannot be combined in the composite good $x$.

4. For simplicity, we ignore taxes in our model.

5. Wales uses the 1972 Panel Study of Income Dynamics from the University of Michigan.

6. We specify land rent gradient $p(h)$ such that $\partial p / \partial j=0$ and wage gradient $w(j)$ such that $\partial w / \partial h=0$. For justification of this specification see White $(1988,138)$.

7. These conditions are satisfied by households in this model because they will locate on a ray from the origin through their job location, but farther out than their job location, to minimize the costs of land and commuting.

8. See also the discussion of the value of commuting time in section 3 which motivates the expression of commuting costs in terms of the wage rate as in equation (32). In single worker households where all income is earned, households with higher incomes have more skilled workers. This situation reduces the incentives for them to locate farther from the city centre as discussed in section 2 .

9. Most of this literature ignores the intrinsic spatial character of job search so that adaptation of the literature is not direct.

10. The literature on commuting and discrimination by race and sex is too extensive to consider in this survey. For an expanded discussion, see Simpson (1992, chapter 5).

11. That is, the wage required by a household to accept a job at location $j$. As $j$ increases, the reservation wage declines because of the locational advantage in terms of commuting and land costs. Households search until they find a wage offer at a particular location that exceeds their reservation wage at that location.

12. The 'islands economy' is used by Phelps (1970) and Lucas and Prescott (1974) to analyze the macroeconomic implications of job search. In their models, however, all workers on any island at any time find employment on that island. If they wish to work on another island next period, they must migrate to that island for the next period. In Simpson's model workers may find employment permanently on other islands and commute daily to those jobs. Thus the islands of Phelps and Lucas and Prescott are regional labour markets in the usual sense while Simpson's islands are intraurban local labour markets.

13. that is, the area over which firms must recruit their work force, given the competition from other firms.

14. The residential location equation is a standard one in the sense of the analysis surveyed in sections 2 and 4 . The model is taken from Siegel (1975), who also finds a stronger relationship for workplace location than residential location in explaining urban structure in the San Francisco Bay area. His analysis of workplace choice is, however, perfunctory.

\section{References}

Alonso, William (1964) Location and Land Use, Cambridge, Mass.: Harvard University Press

Beckmann, Martin (1974) Spatial equilibrium in the housing market, Journal of Urban Economics 1, 99-107.

Beesley, M. E. and Dalvi, M. Q. (1974) Spatial equilibrium and the journey to work, Journal of Transport Economics and Policy 8, 197-222.

Brueckner, J. K. (1987) 'The structure of urban equilibria: a unified treatment of the Muth-Mills model, in Edwin Mills (1987), 821-45. 
Evers, Gerard and van der Veen, Anne (1986) 'Commuting, migration and labor force participation: micro and macro economic approaches, unpublished Ph.D. Dissertation (in Dutch), University of Tilburg, the Netherlands.

Hamilton, Bruce (1982) Wasteful commuting, Journal of Political Economy 1035-53.

Hekman, John (1980) Income, labor supply, and urban residence, American Economic Review 70, 805-11.

Henderson, J. Vernon (1985) Economic Theory and the Cities, New York: Academic Press.

Kain, John (1962) The journey-to-work as a determinant of residential location, Papers and Proceedings of the Regional Science Association 9, 137-60.

- (1968) Housing segregation, negro employment, and metropolitan decentralization, Quarterly Journal of Economics 82, 175-97.

Kohlhase, Janet (1986) Labor supply and housing demand for one- and two-earner households, The Review of Economics and Statistics 68, 48-57.

Leonard, Jonathan (1987) The interaction of residential segregation and employment discrimination, Journal of Urban Economics 21, 323-46.

Lucas, Robert, and Prescott, Edward (1974) Equilibrium search and unemployment, Journal of Economic Theory 7, 188-209.

McCormick, Barry (1986) Employment opportunity, earnings, and the journey to work of minority workers in Great Britain, Economic Journal 96, 375-97.

Madden, Janet, and White, Michelle (1980) Spatial implications of increases in the female labor force: a theoretical and empirical synthesis, Land Economics 56, no. 4.

Mills, Edwin (1972) Studies in the Structure of the Urban Economy, Baltimore: Johns Hopkins Press.

- (1987) Handbook of Regional and Urban Economics: Volume 2, Urban Economics Amsterdam: North-Holland.

Moses, Leon (1962) Towards a theory of intra-urban wage differentials and their influence on travel patterns, Papers and Proceedings of the Regional Science Association 9, $53-63$.

Muth, Richard (1969) Cities and Housing, Chicago: University of Chicago Press.

Oi, Walter (1976) Residential location and labor supply, Journal of Political Economy $84, \mathrm{~S} 221-\mathrm{S} 247$.

Phelps, Edmund (1970) Introduction: the new microeconomics in employment and inflation theory in Edmund Phelps et al (eds.) Microeconomic Foundations of Employment and Inflation Theory, New York: Norton.

Rees, Albert, and Shultz, George (1970) Worker and Wages in an Urban Labor Market, Chicago: University of Chicago Press.

Scott, Allen (1982) Locational patterns and dynamics of industrial activity in the modern metropolis, Urban Studies 19, 111-42.

Siegel, Jay (1975) Intrametropolitan migration: a simultaneous model of employment and residential location of white and black households, Journal of Urban Economics 2, $29-47$.

Simpson, Wayne (1977) Imperfect Knowledge, Urban Structure and Labour Market, unpublished Ph.D dissertation, London School of Economics.

- (1980) A simultaneous model of workplace and residential location incorporating job search, Journal of Urban Economics 8, 330-49.

(1987) Workplace location, residential location, and urban commuting, Urban Studies 24, 119-28.

(1989) Urban structure and workplace choice: theory and applications, paper presented to the 29th European Congress of the Regional Science Association, Cambridge, U.K., August.

- (1992) Urban Structure and the Labour Market: Analysis of Worker Mobility, Commuting, and Underemployment in Cities. Oxford: Oxford University Press, forthcoming. 
Straszheim, Mahlon (1987) The theory of urban residential location, in Edwin Mills (1987), 717-57.

Wales, Terence (1978) Labour supply and commuting time, Journal of Econometrics 8, 215-26.

Wheaton, William (1977) Income and urban residence: an analysis of consumer demand for location. American Economic Review 67, 620-31.

White, Michelle (1988) Location choice and commuting behavior in cities with decentralized employment, Journal of Urban Economics 24, 129-52. 